\title{
Crossed aphasia in a dextral without "minor" hemisphere signs
}

\author{
J.C. Marshall and P.W. Halligan \\ University Department of Clinical Neurology, and The Radcliffe Infirmary, Oxford and \\ Rivermead Rehabilitation Centre, Oxford, UK \\ Correspondence to: J.C. Marshall, Neuropsychology Unit, University Department of Clinical \\ Neurology, The Radcliffe Infirmary, Woodstock Road, Oxford OX2 6HE, UK
}

\begin{abstract}
A case of severe aphasia after right hemisphere stroke, confirmed by CT, in an unambiguously dextral patient is reported. The patient showed no limb apraxia, and performed well on a test of "closure" (Mooney faces). Extensive testing revealed no signs of visuo-spatial neglect. We conclude that "pure" crossed aphasia can occur in the absence of symptoms normally associated with right hemisphere lesions.
\end{abstract}

Keywords: Crossed aphasia - Stroke - Visuo-spatial disorders

\section{INTRODUCTION}

Aphasia due to right hemisphere lesions in right-handed people is a very rare condition. Over the last hundred years, only a hundred or so such patients have been reported. The exact number depends upon the comprehensiveness of the reviewer's literature search, and his or her evaluation of how convincing is the report. Castro-Caldas et al. (1987) are prepared to accept 120 cases, Faglia et al. (1990) initially consider 87 cases, and Joanette et al. (1982) 72 cases, drawn from the literature extending back to 1880 . Yet not all of these purported cases carry equal conviction. If patients are excluded where the unilateral nature of the lesion was suspect, where the patient's handedness was not adequately determined, where aphasia was insufficiently documented, or where such "environmental" factors as bilingualism or illiteracy are found, the number of cases remaining falls precipitously. Faglia et al. (1990) are prepared to accept 26 cases as reliable; Joanette et al. (1982) and Habib et al. (1983) only accept 11 . With the advent of functional imaging techniques, it is also desirable to rule out the possibility of "crossed diaschisis" (Perani et al., 1988; Ferro et al., 1991).

Granted, then, that crossed aphasia exists in genuine dextrals (however infrequent it may be), the next question concerns the additional symptomatology that may be associated with anomalous language disorder. The consensus is that crossed aphasia is usually, but not invariably, found in conjunction with signs of visuo-spatial or perceptual disorder that are characteristic of right hemisphere lesion in more typical patients without language disorder (Coppens and Robey, 1992).
Constructional apraxia with loss of spatial relations (McFie and Zangwill, 1960) and left neglect are the two most commonly reported associates of crossed aphasia (Castro-Caldas et al., 1987; Joanette, 1989); this clearly suggests that, in some patients at least, the right hemisphere is dominant for both language and (some aspects of) visuo-spatial cognition (Basso et al., 1985; Faglia and Vignolo, 1990). As Henderson (1983) reports, right hemisphere dominance for language "does not preclude ipsilateral specialization for visuospatial functions".

In many cases of crossed aphasia, spatial skills have not been fully investigated. It thus remains possible that in patients with severe aphasia after large right hemisphere lesions, there will always be some degree of spatial impairment. That is, the basic specialization of the right hemisphere for visuo-spatial functions may not be susceptible to significant biological variation. This, then, is the question we address in the current case study.

\section{CASE REPORT}

R.C. a 49-year-old woman, is a fully right-handed, monolingual English speaker. She scores $12 / 12$ on the Edinburgh Handedness Inventory (Oldfield, 1971); there is no family history of left handedness, although one of two sons is ambidextrous. The patient suffered a stroke with dense left hemiplegia and gross aphasia on 20 November 1991. There was no significant medical history other than

Behavioural Neurology . Vol 5 . 1992

247 
migraines, although there is a family history of ischaemic heart disease. A CT scan (Fig. 1) showed a recent infarction in the territory of the right middle cerebral artery involving the inferior posterior frontal lobe, internal capsule, putamen, claustrum, caudate nucleus and insula cortex. There was no haemorrhage present and other than compression of the anterior horn of the right lateral ventricle the left hemisphere was not involved. By 25 February 1992, there remained a moderately severe left hemiparesis; R.C. scored $33 \%$ and $42 \%$, respectively, in the arm and leg assessments on the Motricity Index. Sensation was normal and visual fields were full to confrontation, without extinction. Functionally, she was moderately dependent, scoring 15/20 on the Barthel ADL Index. The neuropsychological assessments were conducted 4 months after the stroke. The patient died (of stomach cancer) before follow-up testing could be conducted.

\section{LANGUAGE EXAMINATION}

The character of R.C.'s spontaneous speech can be seen from the following transcript. She is attempting to report what she had been doing between our first and second examinations:

"Er . . . well, I've had a cold . . . and a cold . . . and another cold. And we walked .... er .... ambulance. And zisio (physio) .... and, oh, Bill picked me up and ... talked (took) me car ... er ... what's the name? Shopping. I'm having another one (gestures toward the patio) ... these ... and Colin is having Fred on and digging, and is mostly ... is laying . . . and it's most (almost) Easter . . Colin and Fred has ... brick ... bricklaying. Wood, furniture up there. But I go and sit out . . . and my swing bed . . . and a table and chairs and a swimming pool . . . and an umbrella (laughs: it is raining outside)."

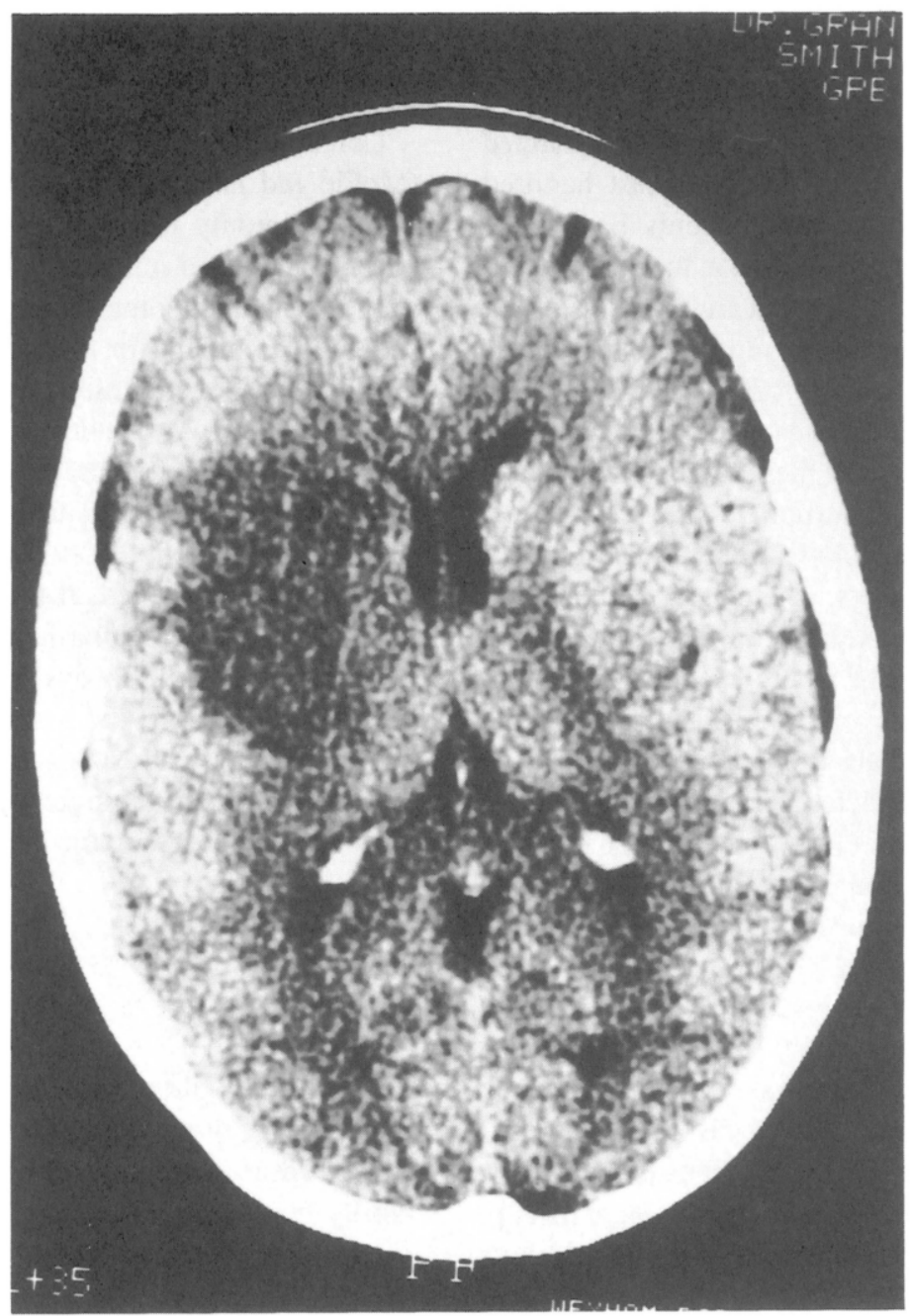

FIG. 1. CT scan of patient R.C. Left is on the right of the image. 
Picture description is equally impaired. Her Cookie Jar description is:

"Well . . . em . . . stool on a chair . . . eating . . . cooking . . . chair ... chair's falling over ... and ... and ... the woman is . . . at the sink . . . and it's turned with water . . . and the chair's . . . em . . . sunny ... well, laughing . . . the girl and the stool."

Prosody, including affective prosody, was normal (within the limits of the gross expressive aphasia). The patient could make linguistic jokes even with her limited language. There was a full range of affect, conveyed both verbally and through facial expression; mood was appropriate, with good insight into her condition. Shortly after the stroke, but not at the time of our investigation, R.C.'s family reported that her accent sounded Italian or French (Gurd et al., 1988).

Naming to visual confrontation was poor. R.C. scored 24/36 correct on the Oldfield-Wingfield test (Oldfield and Wingfield, 1965). All errors were either circumlocutions (usually with a detailed and fully appropriate gesture) or semantically related items (e.g. stethoscope-“ears ... chest"; cigarette-“smoking"; anchor-“ship"; lamp"switch on").

Articulation was not impaired; there was no evidence of awkwardness or distortion. Phonological paraphasias were very rare (physio_-"zizio"), but sematic paraphasias were common: "And this shoulder, oh, the hurt" (pain); "We had a chicken" (turkey); "I'll be covered [busy] in [with] cooking."

Comprehension failure was sometimes apparent in informal conversation and was easily demonstrable on formal testing. On Complex Ideational Material from the BDAE (Goodglass and Kaplan, 1983), R.C. scored 6/12. On the Test for Reception of Grammar (Bishop, 1983), R.C. passed only four blocks from sections D to T; these were $\mathrm{D}, \mathrm{E}, \mathrm{H}$ and $\mathrm{J}$ (i.e. simple active or negative sentences, singular and plural). Digit span was four items forward, and two backward.

Reading aloud was slow and hesitant but with very few overt errors for either single words or simple paragraphs. She correctly read 32/36 names of the Oldfield-Wingfield pictures; errors were phonologically based (e.g. gyroscope-_skyroscope"; xylophone-“exaklyphone"). A 44-word passage was read with only three errors: the same text with randomized word order was read with two errors. No error was characteristic of neglect dyslexia (e.g. after-“a few"; bridge_-"bringed"; fed_-“found").

\section{PRAXIS AND VISUO-SPATIAL EXAMINATION}

On the BDAE apraxia tests (Goodglass and Kaplan, 1983), there was no evidence of bucco-facial apraxia to oral command $(5 / 5)$, or of intransitive $(5 / 5)$ or transitive (5/5) limb apraxia. R.C.'s copy of the Rey figure, although poorly executed, showed no evidence of constructional apraxia (Warrington, 1969). The copy did not show the lack of detail and poor outline chracteristic of left hemisphere cases; neither did it show the gross fragmentation and loss of spatial relationships characteristic of right hemisphere patients. R.C. was given five visuo-spatial tests from the Behavioural Inattention Test (Halligan et al., 1991). Her performance was errorless on star cancellation (54/54), letter cancellation (40/40), copying simple shapes (4/4), and representational drawing (3/3). She scored $8 / 9$ (within normal limits) on line bisection (three lines staggered across an A4 page).

To investigate bisection further, R.C. was given horizontal lines that ranged from 18 to $180 \mathrm{~mm}$ in steps of $18 \mathrm{~mm}$. For each line length (presented in pseudo-random order), she undertook 10 bisection trials. The results (mean and standard deviation) are shown in Table 1. Transection displacements at all lengths were well within normal limits (Manning et al., 1990), and were in the opposite direction ( $-=$ leftward displacement) to those found in patients with left neglect after right hemisphere damage.

Finally, R.C. was required to identify the first 26 faces from Lansdell's modification of Mooney's closure test (Newcombe, 1969). The task requires that a partially delineated face (white contour on black or vice versa) can be perceived and then identified as male or female and young or old. As the patient could not reliably say "man" or "woman" or "young" or "old", she accordingly specified sex in terms of "boy" or "girl", and age with an estimate of the number of years old. Using these responses, her score $(21 / 26)$ was within normal limits (Newcombe, 1969).

\section{DISCUSSION}

R.C. is unquestionably aphasic, and, with a few exceptions, the character of her aphasia would not be perceived as peculiar had she suffered a left hemisphere stroke. The

TABLE I. Accuracy of horizontal line bisection in patient R.C.

\begin{tabular}{ccc}
\hline $\begin{array}{c}\text { Line } \\
\text { length } \\
(\mathrm{mm})\end{array}$ & $\begin{array}{c}\text { Mean } \\
\text { transection } \\
\text { displacement } \\
(\mathrm{mm})\end{array}$ & $\begin{array}{c}\text { Standard } \\
\text { deviation }\end{array}$ \\
\hline 18 & -1.3 & \\
36 & -2.9 & 0.8 \\
54 & -2.5 & 1.5 \\
72 & -2.8 & 2.4 \\
90 & -1.6 & 2.5 \\
108 & -0.7 & 2.2 \\
126 & -0.6 & 4.2 \\
144 & -2.2 & 4.8 \\
162 & -0.2 & 5.3 \\
180 & -0.6 & 3.7 \\
\hline
\end{tabular}


absence of bucco-facial apraxia or any clear articulatory problems is perhaps atypical, as is her relatively wellpreserved ability to read aloud. In some other cases of crossed aphasia, limb apraxia and constructional apraxia have been reported as absent, as in our patient (Castro-Caldas et al., 1987; Alexander et al., 1989).

R.C. also scores within normal limits on a test of visual closure (Mooney faces) that is a highly sensitive indicator of right hemisphere damage. The lesion site that provokes gross problems on this test is usually temporal (or temporoparietal), but the test is also sensitive to frontal right hemisphere damage (Newcombe, 1969). Although the paradigmatic lesion site for left visuo-spatial neglect is right parietal, it is well established that right frontal lesions often cause severe left neglect (Heilman and Valenstein, 1972; Damasio, 1980). Testing for neglect in R.C. involved performance on visuo-motor tasks that are sensitive to frontal neglect (Liu et al., 1992).

Thus despite right hemisphere damage sufficient to cause profound and lasting aphasia, R.C. shows no signs whatsoever of left neglect on any of our non-verbal or verbal (reading) tasks. Our investigation of neglect was more extensive than in previously reported cases. We therefore conclude that R.C. may represent a relatively "pure" case of crossed dominance; all core language skills are represented in the (damaged) right hemisphere and many core visuo-spatial and perceptual skills in the (intact) left hemisphere. R.C. and her parents were all right handed, and we would not want to postulate familial left handedness solely on the basis of one ambidextrous son (see Alexander et al., 1989). Atypical cerebral organization can, it seems, be a "mirror image" (Alexander et al., 1989) of normality.

\section{Acknowledgements}

This work was supported by the Medical Research Council. We also thank Drs Freda Newcombe and Derick Wade for many helpful contributions.

\section{REFERENCES}

Alexander MP, Fishette MR and Fisher RS (1989) Crossed aphasias can be mirror image or anomalous: case reports, review and hypothesis. Brain, 112, 953-973.

Basso A, Capitani E, Laiacona M and Zanobio ME (1985) Crossed aphasia: one or more syndromes? Cortex, 21 25-45.

Bishop D (1983) Test for Reception of Grammar (TROG): Test Booklet and Manual. University of Newcastle upon Tyne, Newcastle upon Tyne.

Castro-Caldas A, Confraria A and Poppe P (1987) Non verbal disturbances in crossed aphasia. Aphasiology, 1, 403-413.

Coppens P and Robey RR (1992) Crossed aphasia: new perspectives. Aphasiology, 6, 558-596.

Damasio AR, Damasio H and Chui HC (1980) Neglect following damage to frontal lobe or basal ganglia. Neuropsychologia, 18, 123-132.

Faglia L and Vignolo LA (1990) A case of "crossed aphasia" in which the integrity of the left hemisphere is assessed by MRI. Italian Journal of Neurological Sciences, 11, 51-55.

Faglia L, Rottoli MR and Vignolo LA (1990) Aphasia due to lesions confined to the right hemisphere in right handed patients: A review of the literature including the Italian cases. Italian Journal of Neurological Sciences, 11, 131-144.

Ferro JM, Cantinho G and Baeta E (1991) Transient crossed aphasia: a case study with SPECT. Behavioural Neurology, 4 75-79.

Goodglass H and Kaplan E (1983) The Assessment of Aphasia and Related Disorders. Philadelphia: Lea and Febiger.

Gurd JM, Bessell NJ, Bladon RAW and Bamford JM (1988) A case of foreign accent syndrome, with follow up, clinical, neuropsychological and phonetic descriptions. Neuropsychologia, 26, 237-251.

Habib M, Joanette Y, Ali-Cherif A and Poncet M (1983) Crossed aphasia in dextrals: a case report with special reference to site of lesion. Neuropsychologia, 21, 413-418.

Halligan PW, Cockburn J and Wilson B (1991) The behavioural assessment of visual neglect. Neuropsychological Rehabilitation, 1, 5-32.

Heilman KM and Valenstein E (1972) Frontal lobe neglect in man. Archives of Neurology, 22, 660-664.

Henderson V (1983) Speech fluency in crossed aphasia. Brain, 106, 837-857.

Joanette Y (1989) Aphasia in left handers and crossed aphasia In: Handbook of Neuropsychology (Eds F Boller and J Grafman), Vol 2. Elsevier, Amsterdam.

Joanette Y, Puel M, Nespoulous JL, Rascol A and Lecours AR (1982) Aphasie croisee chez les droitiers: I. Revue de la litterature. Revue Neurologique, 138, 575-586.

Lui GT, Bolton AK, Price BH and Weintraub S (1992) Dissociated perceptual-sensory and exploratory-motor neglect. Journal of Neurology, Neurosurgery and Psychiatry, 55, 701-706.

Manning L, Halligan PW and Marshall, JC (1990) Individual variation in line bisection: a study of normal individuals with application to the interpretation of visual neglect. Neuropsychologia, 28, 647-655.

McFie J and Zangwill OL (1960) Visual constructive disabilities associated with lesions of the left cerebral hemisphere. Brain, 83, 243-260.

Newcombe F (1969) Missile Wounds of the Brain: A Study of Psychological Deficits. Oxford University Press, Oxford.

Oldfield RC (1971) The assessment and analysis of handedness: The Edinburgh Inventory. Neuropsychologia, 9, 97-113.

Oldfield RC and Wingfield A (1965) A series of pictures for use in object-naming. MRC Psycholinguistics Unit Special Report, PLU/65/19.

Perani D, Papagno C, Cappa S, Gerundini P and Fazio F (1988) Crossed aphasia: functional studies with single photon computerised tomography. Cortex, 24, 171-178.

Tanridag O and Ongel C (1989) Transcortical motor aphasia due to a right hemisphere lesion in a right-handed man. Aphasiology 3, 717-721.

Warrington EK (1969) Constructional apraxia. In: Handbook of Clinical Neurology (Eds PJ Vinken and GW Bruyn), Vol 4. North-Holland, Amsterdam. 


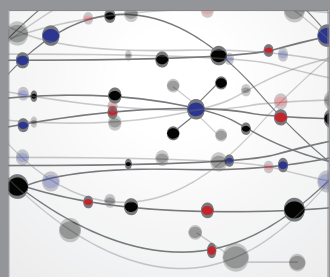

The Scientific World Journal
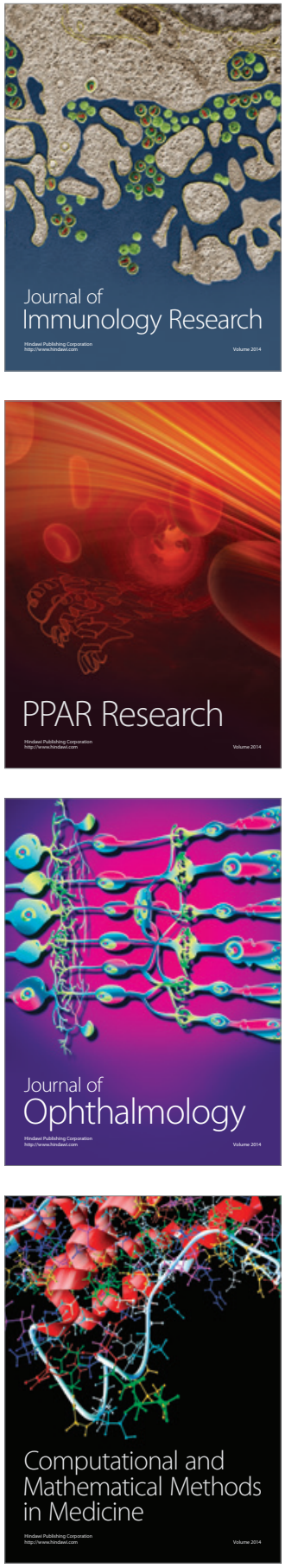

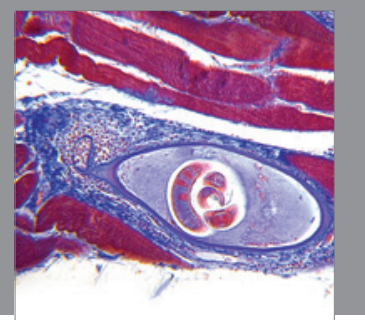

Gastroenterology

Research and Practice
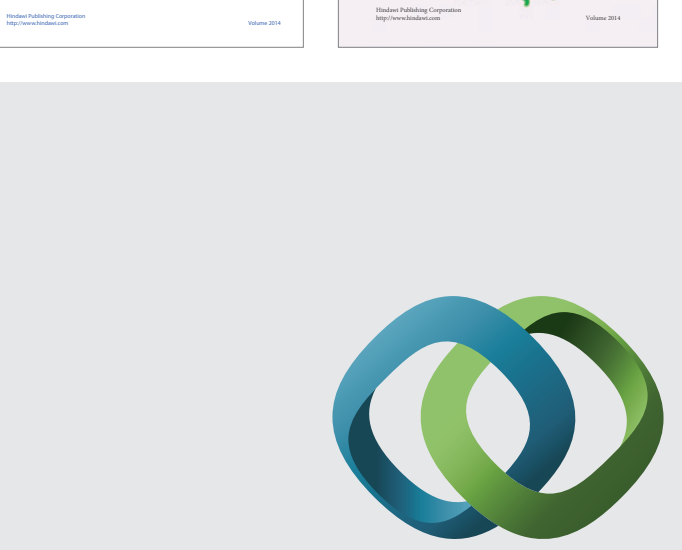

\section{Hindawi}

Submit your manuscripts at

http://www.hindawi.com
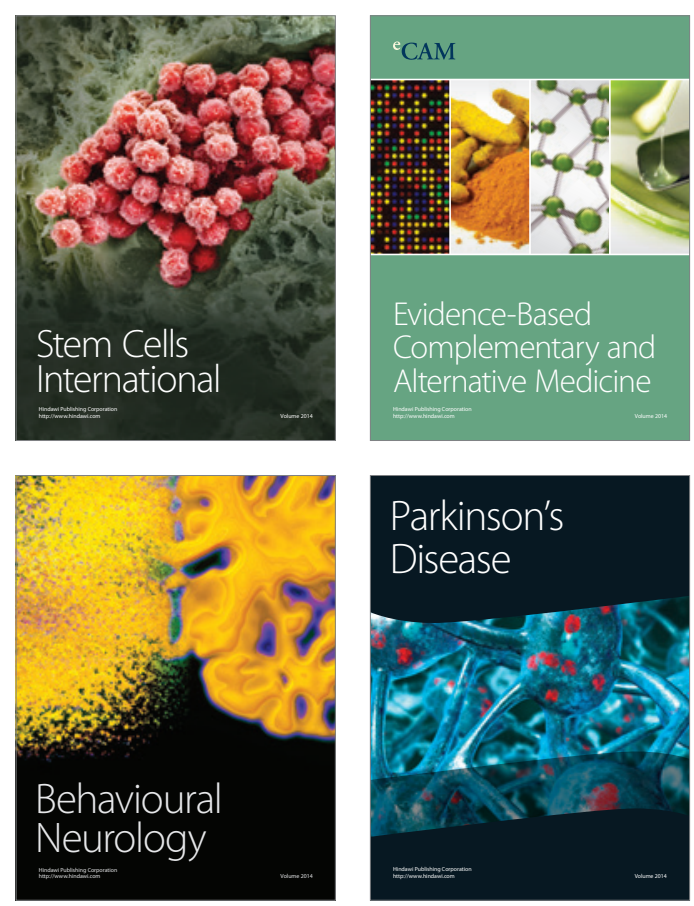

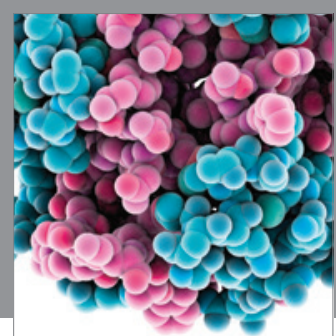

Journal of
Diabetes Research

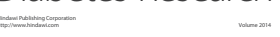

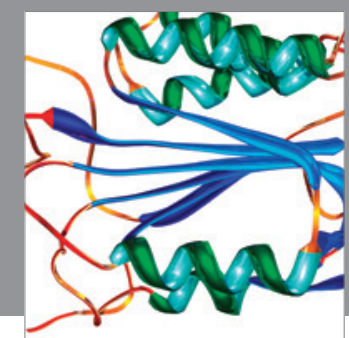

Disease Markers
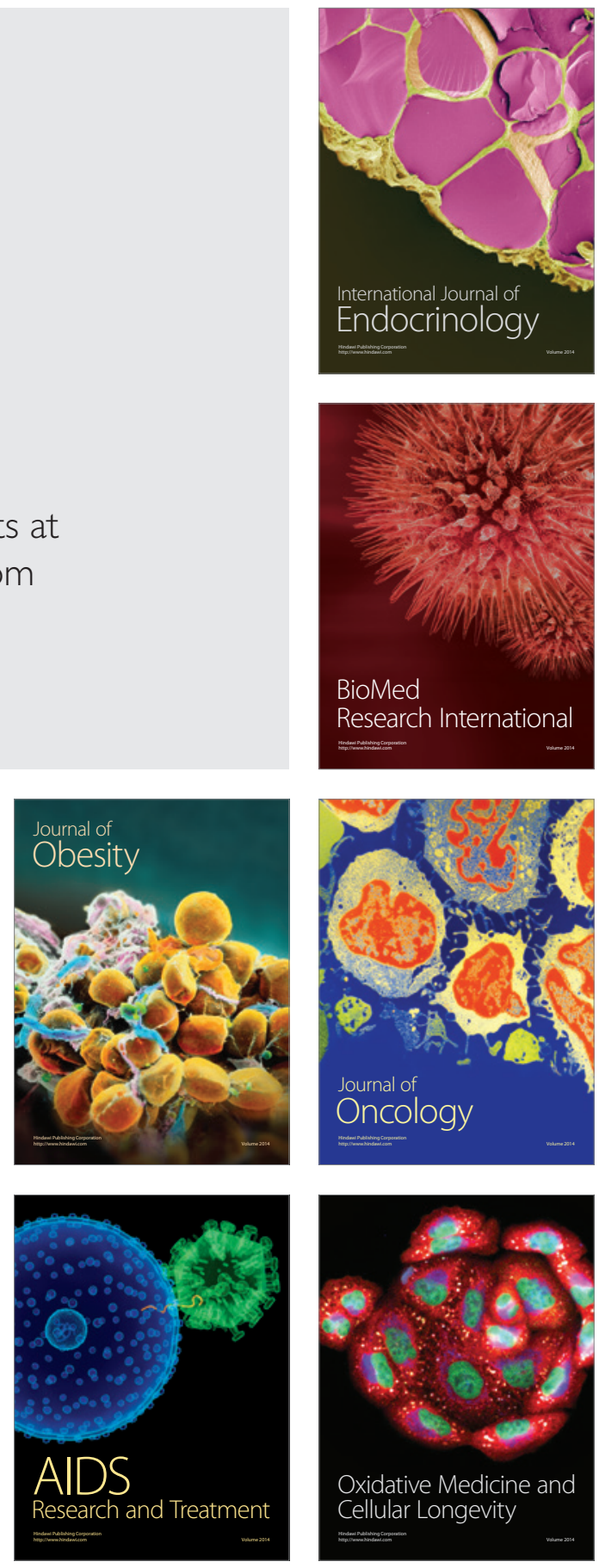